\section{Diversity between Jatropha curcas L. accessions based on oil traits and X-ray digital images analysis from it seeds}

\author{
Milena Silva Pinto ${ }^{1}$, Pedro Corrêa Damasceno Junior ${ }^{1 *}$, Lucas \\ Couto de Oliveira ${ }^{1}$, Adelia Ferreira de Faria Machado ${ }^{2}$, Marco \\ Andre Alves de Souza ${ }^{3}$, Dandara Rêgo Muniz ${ }^{4}$ and Luiz Antônio \\ dos Santos Dias ${ }^{4}$
}

\begin{abstract}
Jatropha curcas L. is a species with high potential for the biodiesel production. Therefore, the oil yield and quality from it seeds should be known. This study aimed to estimate the correlation between morphological traits, yield and oil quality evaluated in the seeds, to know the genetic diversity between J. curcas accessions and it behavior regarding to three harvest seasons. For this purpose, X-ray digital images from seeds of 18 accessions were obtained, and the seeds analyzed for external and internal morphological aspects. The same seeds were analyzed for oil yield and quality. In general, the results concerning diversity indicated a narrow genetic base. More rounded and very long seeds had lower oil yield. Larger seeds presented higher oil yield only when their internal cavity was filled by their endosperm. Most of the accessions showed variation regarding the size of the endosperm, yield and oil quality between harvest seasons.
\end{abstract}

Key words: Yield and oil quality, seed morphology, endosperm seed, high-quality phenotyping.

\section{INTRODUCTION}

Jatropha curcas L. belongs to the Euphorbiaceae family, and its genus comprises about 500 species. The specie is diploid with $2 n=2 x=22$ chromosomes (Dahmer et al. 2009). The probable origin center of Jatropha species is Central America (Fairless 2007, Dias et al. 2012), but it is widely occurring in several parts of the globe, such as South America, Africa and Asia. In Brazil, its occurrence extends from north to south.

Nowadays, J. curcas crop stands out as an important source of raw material for biodiesel production. According to Akbar et al. (2009) the oil of the species has appropriate physic-chemical characteristics to be used for biodiesel production. Also, according to Maina (2014), its transesterified oil has characteristics suitable for use in diesel engines, resulting in carbon lower emissions and improved engine performance.

In Brazil, breeding programs of the species have generally not prioritized the selection of genotypes containing seeds with high yield and oil quality. Fairless (2007) and Achten et al. (2010) argue that J. curcas is an undomesticated species.
Crop Breeding and Applied Biotechnology 18: 292-300, 2018 Brazilian Society of Plant Breeding. Printed in Brazil http://dx.doi.org/10.1590/1984$70332018 v 18 n 3 a 43$
${ }^{*}$ Corresponding author:
E-mail: damascenojunior2009@gmail.com

Received: 29 May 2018 Accepted: 03 June 2018

${ }^{1}$ Universidade Federal Rural do Rio de Janeiro, Departamento de Fitotecnia, 23.897000, Seropédica, RJ, Brazil

${ }^{2}$ Embrapa Tecnologia de Alimentos, 23.020470, Rio de Janeiro, Brazil

${ }^{3}$ Universidade Federal Rural do Rio de Janeiro, Departamento de Química, 23.897-000,

Seropédica, RJ, Brazil

${ }^{4}$ Universidade Federal de Viçosa, Departamento de Fitotecnia, Campus Universitário, 36.590-900, Viçosa, MG, Brazil 
The selection is made basically based on the grains yield. Aspects related to the genetic potential for traits related to the seeds themselves are still little explored in the existing germplasm, according to Rocha et al. (2012) and Kaushik et al. (2007). Although the J. curcas yield components are extensively studied (Rao et al. 2008, Spinelli et al. 2010, Reis et al. 2015), higher yields and oil quality will be achieved when detailed seed studies were implemented.

In this sense, high-quality phenotyping becomes essential in the detailed study of external and internal aspects of the seeds of the species. Researches on this subject are practically non-existent for the $J$. curcas. Obtaining X-rays from the seeds together with subsequent digital analysis of the images can be powerful tools in the search for a high-quality phenotype. The X-ray allows the seed to be viewed externally and internally in a thorough manner without destroying it, which enables additional evaluations such as, for example, the extraction and analysis of the oil in the same seeds. This strategy will undoubtedly lead to more consistent information on the subject. Studies of this nature will allow in the future to know the ideotype for seeds that exhibit high yield and oil quality in plants with high productive potential.

Initially the present work aimed to know the genetic diversity between accessions of $J$. curcas as the characteristics related to oil content and quality and seed morphology, with the latter estimated from the digital analysis of X-ray images. In relation to the same variables, we also sought to know the correlation between them and the behavior of each accession during three distinct periods of seed harvest. With all this information, the final objective was to discuss an ideotype for the J. curcas seeds, which at the same time added high yield potential and oil quality in these seeds.

\section{MATERIAL AND METHODS}

\section{Location and germplasm studied}

The research was carried out at the Universidade Federal Rural do Rio de Janeiro (UFRRJ), campus of Seropédica (lat $22 \circ 45^{\prime} \mathrm{S}$, long 43 $41^{\prime} \mathrm{W}$ and alt $26 \mathrm{~m}$ asl), RJ, Brazil. The procedures related to analyses of oil content and fatty acid composition were carried out at Laboratory of Oils and Fats of EmbrapaTecnologia de Alimentos (Rio de Janeiro, RJ, Brazil). The seeds were collected from 18 accessions belonging to the J. curcas germplasm Collection of the Departamento de Produção Vegetal at UFRRJ (Reis et al. 2015), planted randomly in spacing $3.0 \times 2.0 \mathrm{~m}$.

\section{Seed harvest, X-ray images and digital analysis}

The seeds were harvested from each accession, in three distinct seasons: in the first and second fortnight of January, and first half of February of of 2013. The seeds were immediately identified according to accession and distinct harvest seasons. Then, they were organized by genotype on a sheet of cardboard paper. Each genotype was organized by the three harvests, the first harvest in the upper portion, the second harvest in the middle portion and the third harvest in the lower portion. Each harvest was organized with three rows of 10 seeds, totaling 90 seeds by genotype. After assembly, the 18 sheets of cardboard paper were taken to the Hospital Veterinário of the UFRRJ, where they were, one at a time, radiographed, revealed on X-ray slides and coupled in negatoscope, which corresponded to one genotype and their three harvests. X-ray images were digitized by Canon Rebel's EOS T5i 18.0 Megapixel digital camera and processed and analyzed digitally by ImageJ Program, version 1.48v (Rasband 2002). Figure 1 illustrates the sequence used in image

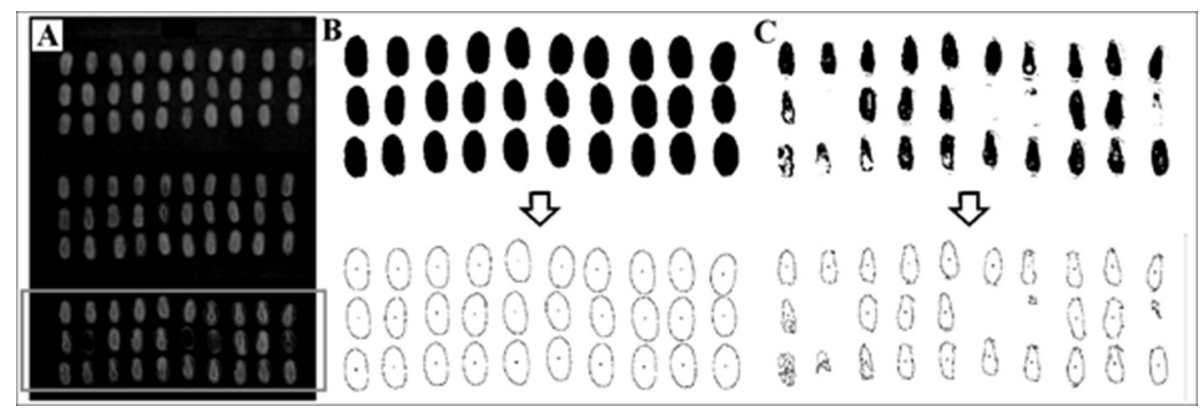

Figure 1. Sequence indicating the steps used in processing and digital analysis of the Jatropha curcas seeds X-ray images by Image program. X-ray image containing seeds from three harvest seasons, highlighting the third harvest (A). Seed area of the third harvest (above) and result processing (below) (B). Seed endosperm area of the third harvest (above)and result processing (below)(C). 
processing and area analysis. After images processing, the scale in centimeters was defined by a bar of know size in the $X$-ray images, which made it possible to calculate the pixels number per centimeter in each analyzed image. We used the tools "Measure" and "Analyze Particles" to analyze the digital images.

\section{Oil content and fatty acid composition of X-ray seeds}

These analyses were performed using the same X-ray seeds. The oil content was determined according to the official method of AOCS (2010). The seeds collected from J. curcas fruits were dried in an air-circulating oven at $60^{\circ} \mathrm{C}$. Afterwards, the seeds were grinded and the oil was extracted for 16 hours in Soxhlet apparatus using petroleum ether $\left(30-60^{\circ} \mathrm{C}\right)$ as solvent. For fatty acid composition analysis of $J$. curcas seeds oil, the methyl esters of fatty acids were prepared according to Hartman and Lago (1973) in triplicate from each sample and injected once into the chromatograph. Gas chromatography was performed in an Agilent 6890 equipment (Agilent Technologies, CA) fitted with a cianopropylsiloxane capillary column (60 $\mathrm{m} \times 0.32 \mathrm{~mm} \times 0.25 \mathrm{~mm}$, Quadrex, Woodbridge, CT). Initial column temperature was set to $100^{\circ} \mathrm{C}$ and held for $3 \mathrm{~min}$, increased to $150^{\circ} \mathrm{C}$ at $50^{\circ} \mathrm{Cmin}^{-1}$, further increased to $180^{\circ} \mathrm{C}$ at $1{ }^{\circ} \mathrm{Cmin}^{-1}$ and finally increased to 200 ${ }^{\circ} \mathrm{C}$ at $25^{\circ} \mathrm{Cmin}^{-1}$ and held for 10 minutes. Carrier gas used was hydrogen, at $1.4 \mathrm{mLmin}^{-1}$ (measured at $100{ }^{\circ} \mathrm{C}$ ). Injection of $1.0 \mathrm{~mL}$ of a $2 \%$ dichloromethane solution of the sample was done into an injector operating at $250^{\circ} \mathrm{C}$ and split mode (1:50). FID detector was kept at $280^{\circ} \mathrm{C}$. Results were expressed as weight percent (area normalization). Identification of Fatty acid methyl esters was based on comparison of retention times with those of Nu-chek standards 62,79 and 87.

\section{Studied traits}

The morphological traits measured by digital analysis were: seed length(SL) and width (SW), length/width seed ratio (SLW), seed area $\left(\mathrm{SA}\right.$, in $\left.\mathrm{cm}^{2}\right)$, endosperm area $\left(E A\right.$, in $\left.\mathrm{cm}^{2}\right)$, endosperm percentage in the total seed area (EP), seed perimeter (SP, in $\mathrm{cm}$ ), and seed circularity (SC, scaled from 0 to 1). SA, EA and EP were measured by harvesting within each of the 18 accessions. The mean seed weight (MSW), seed bark weight (BW) and endosperm weight (EW) were measured on a digital scale with a precision of $0.01 \mathrm{~g}$. The Oil content of dry matter (OC), saturated(SFA) monounsaturated (MFA) and polyunsaturated fatty acids (PFA) were obtained from the oil extracted of radiographed seeds. The OC was estimated by accession, in each of the three harvests, and the traits SFA, MFA and PFA were measured by accession independent of the harvest season.

\section{Data statistical analysis}

Initially, all data were submitted to descriptive statistical analysis. The averages, minimum and maximum values, standard deviations and variation coefficients were obtained. Pearson's correlation coefficients were also estimated among all variables and organized in a Heatmap. Then the data were staggered and submitted to analysis of the principal components (Dias 1998), aiming to determine the relative importance of each analyzed variable, according to Jolliffe (1972). After this procedure the data matrix was redone, excluding the variables of lesser relative importance. With this new data matrix, genetic diversity was estimated based on two different methodologies, namely: clustering by Tocher optimization and hierarchy by UPGMA (Unweighted pair-group method using an arithmetic average). The data were normalized by division of the value observed by the standard deviation of the corresponding variable. The matrices used in Tocher and UPGMA were obtained via Euclidean distance. The consistency of the cluster analyzes was estimated through cophenetic correlation (Dias 1998). The optimal number of clusters in the UPGMA dendrogram was defined according to Kelley et al. (1996). In order to investigate the stability of accessions regarding seed size and endosperm between harvests, we compared two-way means by the t-test for the variables SA, EA and EP of each of the three harvests, independent of accessions and within each accession. In this case, the average of each harvest was obtained from three replicates, in which they corresponded to each of the three seed lines within each harvest. These can be visualized on the X-ray slides of Figures 1, that is, the upper, middle and lower portions (harvest seasons) are formed by three seed lines (replicates). All statistical analyzes were performed in Program R, version 3.1.2 (R Development Core Team 2014).

\section{RESULTS AND DISCUSSION}

Among all the variables analyzed here, the seed circularity $(\mathrm{SC})$ showed the highest coefficient of variation (CV = $15.61 \%$ ) (Table 1). Circularity values indicate that the closer to 1.0, the more seeds resemble a perfect circle. The mean 
Table 1. Descriptive statistics of traits related to seed morphology, oil content and composition from 18 Jatropha curcas accessions

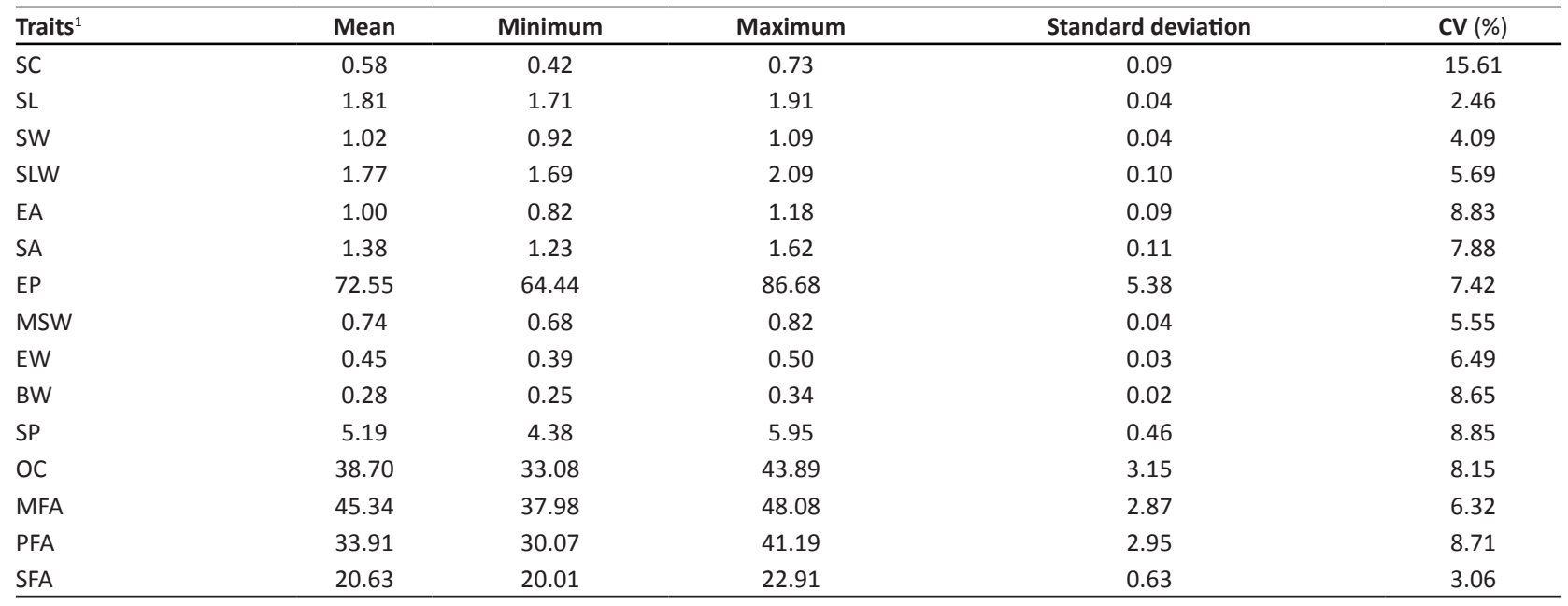

$\mathrm{SC}=$ Seed circularity; $\mathrm{SL}=$ Seed length; $\mathrm{SW}=$ Seed width; SLW = Seed length/width ratio; $\mathrm{EA}=$ Endosperm area $\left(\mathrm{cm}^{2}\right) ; \mathrm{SA}=\mathrm{Seed}$ area $\left(\mathrm{cm}^{2}\right) ; \mathrm{EP}=\mathrm{Endosperm}$ percentage in the total seed area; MSW = Mean Seed weight (g); EW = Endosperm weight (g); BW = Seed bark weight (g); SP = Seed perimeter; OC = Oil content of dry matter (\%); MFA = Monounsaturated fatty acids (\%); PFA = Polyunsaturated fatty acids (\%); SFA = Saturated fatty acids (\%).

SC was estimated at 0.58 , and the minimum and maximum values, respectively, were 0.42 and 0.73 . Mean seed length (SL) was estimated at $1.81 \mathrm{~cm}$. The lowest seed had $1.71 \mathrm{~cm}$, and the largest, $1.91 \mathrm{~cm}$ (Table 1). Reis et al. (2015) and Freitas et al. (2016) found lengths of seeds very close to those found in the present study, with values varying between 1.68 and $1.94 \mathrm{~cm}$, and an average of $1.80 \mathrm{~cm}$. Already Kaushik et al. (2007) found seeds with shorter length, with a minimum of 1.60 and a maximum of $1.76 \mathrm{~cm}$. The mean seed width ( $\mathrm{SW}$ ) analyzed was $1.02 \mathrm{~cm}$, with a variation of 0.92 to $1.09 \mathrm{~cm}$. Values of length and width, respectively, between 1.78 and $1.85 \mathrm{~cm}$ and 0.80 and $0.86 \mathrm{~cm}$ were reported by Santoso (2011) in genotypes from Indonesia. Therefore, seed size smaller than the present work. Rao et al. (2008) found variation between 1.55 and $1.87 \mathrm{~cm}$ for length and between 1.77 and $2.25 \mathrm{~cm}$ for width. Mean seed weight (MSW) showed zero correlation with seed length (SL) and practically null to width (SW) (Figure 2). The length/width ratio (SLW) showed negative correlation of the order of -0.20 with the seed area (SA). Larger seeds area (SA) tended to be wider than long, but not necessarily circular.
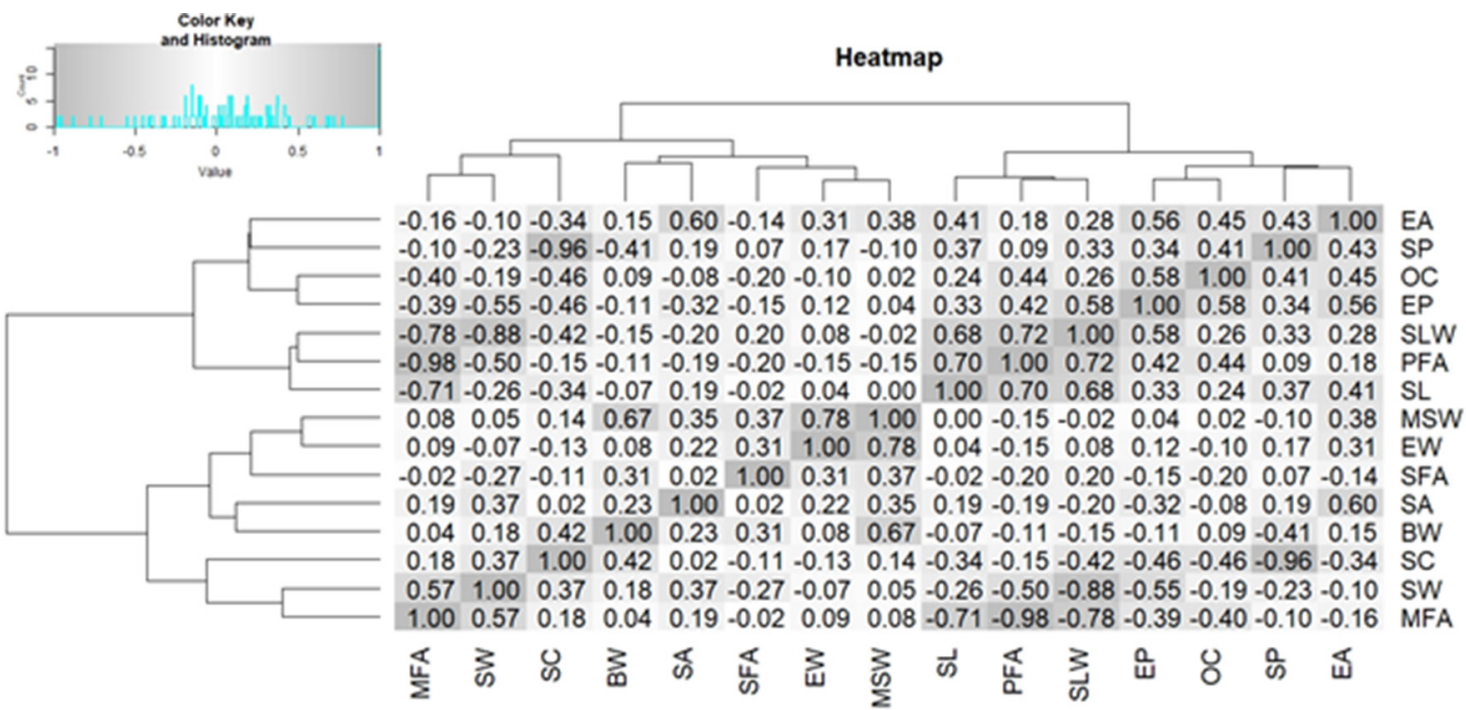

Figure 2. Heatmap based on estimated Pearson's correlation coefficients between variables related to seed morphology, oil content and composition from 18 Jatropha curcas accessions. Heatmap with more gray to high correlations. 
Although the endosperm area (EA) increased with the seed area (SA), the endosperm percentage (EP)occupied in the total seed area did not follow the same trend. The correlation between SA and EA was 0.60 , and SA and EP, -0.32 (Figure 2). The mean number of EP was $72.55 \%$, with a minimum value of 64.44 and a maximum of $86.68 \%$ (Table 1).

In the present work, on average, $60.81 \%$ of the seed weight (MSW) was determined by endosperm weight (EW). This result is in agreement with those reported by Ferrari et al. (2009) and Makkar et al. (1998), where 59.1\% and 61.6\%, respectively, of the seed weight was due to the endosperm. The mean seed weight (MSW) was estimated at $0.74 \mathrm{~g}$, with seeds ranging from 0.68 to $0.82 \mathrm{~g}$ (Table 1). Seed bark weight (BW) exerted a reasonable influence on MSW, with a correlation estimated at 0.67 (Figure 2). Kaushik et al. (2007) estimated in 0.52 the correlation between weight and thickness of the bark of the seed. The correlations between MSW and endosperm area (EA) and seed area (SA) were estimated at 0.38 and 0.35 , respectively (Figure 2), while for MSW and the seed perimeter (SP) the correlation was -0.10 . In view of the above, it is noticed that the increase of MSW does not always result, or proportionally, in the increase of the endosperm and the seed area. The seed endosperm weigh (EW) showed a correlation of 0.31 with the endosperm area (EA), an estimate lower than expected (Figure 2).

The seed oil content (OC) was estimated at $38.7 \%$, with a minimum and maximum value of 33.08 and $43.89 \%$, respectively (Table 1). The correlation between seed weight (MSW) and OC was practically null ( $r=0.02)$ (Figure 2). Kaushik et al. (2007) found a low correlation of 0.23, also confirmed by Reis et al. (2015), between the same variables. However, Freitas et al. (2016) found that oil content was positively and significantly correlated (0.41) with 100-seed weight. The endosperm area (EA) and the endosperm percentage in the total seed area (EP) were shown to be more efficient to estimating the OC than the MSW. The correlation between OC and EA was estimated at 0.45 , and of OC with EP at 0.58 (Figure 2). Larger and heavier seeds, respectively, expressed by SA and MSW, did not translate into increased of OC. It is also observed that there was a negative correlation $(r=-0.46)$ between OC and seed circularity (SC). OC had a low correlation $(r=0.24)$ with seed length (SL) (Figure 2). Already Kaushik et al. (2007) found a negative correlation between seed oil content and seed length.

The correlations between OC with monounsaturated (MFA), polyunsaturated (PFA) and saturated (SFA) fatty acids were estimated at $-0.40,0.44$ and -0.20 , respectively (Figure 2). MFA showed high and negative correlation $(r=-0.71$ ) with seed length (SL). With the seed width (SW), MFA presented a correlation of 0.57 . It is worth mentioning that the PFA concentration tends to increase in longer seeds. The correlation between PFA and MFA was estimated at - 0.98 (Figure 2). According to Akbar et al. (2009), the ideal vegetable oil for synthesis of biodiesel must contain reduced saturation and low polinsaturation, that is, be rich in monounsaturated fatty acid. MFA average was $45.34 \%$ (37.98 to $48.08 \%$ ), that the PFA average was $33.91 \%$ (30,07 to $41,19 \%$ ), and that the SFA average was estimated at $20.63 \%$ (20.01 to $22.91 \%$ ) (Table 1). Similar reports were found by Makkar et al. (1998), Kaushik et al. (2007) and Akbar et al. (2009).

It was observed that PFA, SFA, OC, MSW, SP, EA, LW and SL were the ones that contributed least to diversity, according to the criteria proposed by Jolliffe (1972). In turn, MFA, EW, BW, SC, EP, SA and SW were the most important to the diversity study. However, the dry matter oil content $(\mathrm{OC})$, reported as one of the most important variables for the culture (Spinelli et al. 2010, Reis et al. 2015), was included in the diversity analysis through clustering by Tocher and UPGMA, together with those most relevant variables.

Tocher analysis indicated the formation of three groups. The first group contained $83.33 \%$ of the accesses studied: $1,2,4,5,6,7,8,10,12,13,14,15,16,17$ and 18. Accesses 3 and 11 were allocated in a second group and the access 9 separated alone in a third group. The cophenetic correlation was estimated in $70.0 \%$.

According to methodology proposed by Kelley et al. (1996), the formation of six cluster in the UPGMA dendrogram was observed (Figure 3). Cluster I contained 44.44\% of accessions (2, 4, 10, 12, 15, 16, 17 and 18), cluster II accounted for $27.77 \%$ of accessions $(1,5,6,7$ and 8), cluster III presented only accessions 13 and 14 and the remaining three clusters were formed by a single accession each (3, 9 and 11). The cophenetic correlation coefficient was estimated in $78.8 \%$. Despite the formation of six statistically distinct clusters, it is noticed that almost all accessions (72.21\%) were allocated in only two clusters (I and II). The accessions of cluster II were closer than those of cluster I (Figure 3). The largest group presented, in general, low values of EP and OC, and higher values for SA (Figure 2), corroborating the same trends previously presented by correlation estimates. 
Based on the results found in the diversity analysis, it can be inferred that the genetic base of the accessions for the variables studied here is narrow. The formation of large clusters containing most of the accessions evidences the fact. Regardless of the methodology, the following accessions were dispersed or clustered together: 1, 5, 6, 7 and 8; 4, 12, 15 and 17; 10 and 16; and 13 and 14. Accessions 3 and 11 were the farthest away from all the others.

Among all variables analyzed here, no statistical differences were observed between the general averages of each harvest. It was observed that generally with the passing of the harvest time, the seed area (SA) and endosperm area (EA) increase, and the endosperm percentage in the total seed area (EP). The correlation between SA and EP ( $r=-0.32)$ (Figure 2), already mentioned, corroborate with the observed result.

Table 2 shows that OC presented lower mean in the third harvest (37.44\%). As already shown, increasing seed size does not really translate into increased oil yield. The highest averages for OC occurred in the second harvest, which occurred at the end of January 2013.

When the approach of the SA, EA and EP variables changes from harvest average to accesions, as a rule, it was observed that the general pattern presented above was not followed. For example, concerning to accession 2, the seeds endosperm area (EA) at the first harvest was statistically higher than the second and third harvests (Table 2). Regarding to accession 2 in the third harvest, the results of a larger seeds and a smaller endosperm demonstrated the reduction of the seeds area occupied by endosperm (EP). Moreover, there was a reduction in oil production (OC) (Table 2), corroborating with the correlation estimates between EP and OC, previously presented (Figure 2).

Accession 18 showed increase of the endosperm percentage in the total seed area (EP) from $63.76 \%$ in the first harvest to $73.86 \%$ in the third harvest (Table 2). In order for the accession to present this expressive increase, the endosperm area (EA) also increased from 0.87 in the second harvest to $1.09 \mathrm{~cm}^{2}$ in the third harvest. In accession 8 the reduction of seed area (SA) and endosperm area (EA) was observed in the second harvest (Table 2). As the behavior of SA and EA were similar, the variable EP remained statistically unchanged during the harvests.

Tabela 2. Average of variables related to the seed morphology (SA, EA and EP) and oil content (OC) from 18 Jatropha curcas accessions, measured in three harvest seasons

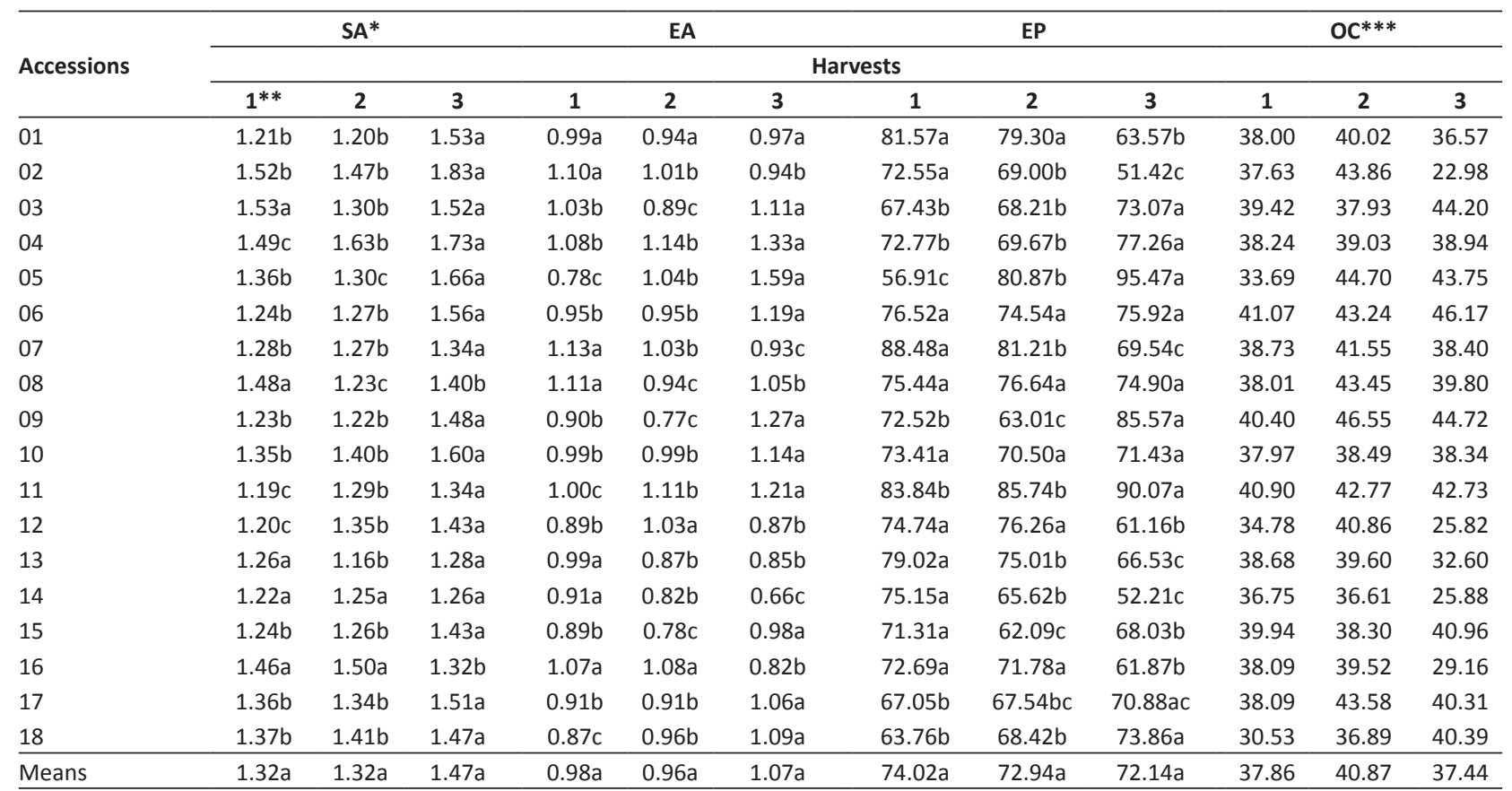

* SA = Seed area $\left(\mathrm{cm}^{2}\right) ; \mathrm{EA}=$ Endosperm area $\left(\mathrm{cm}^{2}\right) ; \mathrm{EP}=$ Endosperm percentage in the total seed area; OC = Oil content of dry matter $(\%) ; * 1,2$ and $3:$ first, second and third harvests, respectively, first and second fortnight of January and first half of February; The SA, EA and EP means was compared two-way means by the t-test. ***The statistical comparison of Oil content means was not performed. 


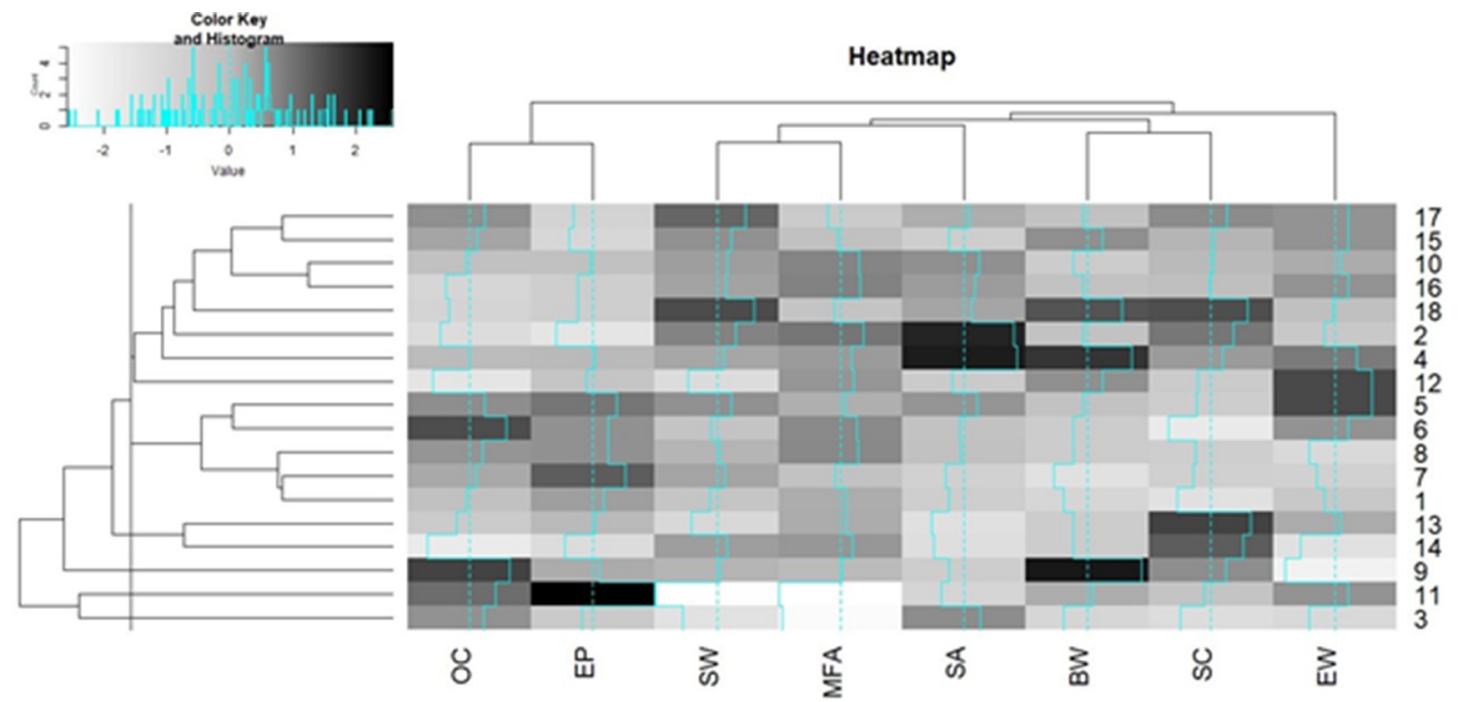

Figure 3. Heatmap organized using UPGMA clustering estimated from the Euclidean distance between 18 Jatropha curcas accessions (axis $\mathrm{Y}$ ) calculated based on the variables related to seed morphology, yield and oil quality (axis $\mathrm{X}$ ).

No doubt, accession 14 showed the greatest difficulties in the endosperm formation, mainly in the third harvest seeds. It can be seen (Table 2) that EA reduced from 0.91 to $0.66 \mathrm{~cm}^{2}$. However, because there was no reduction in the seed area (SA), the occupation of endosperm in the total seed area (EP) had the largest drop among the evaluated accession, estimated at $52.21 \%$ only (Table 2 ). In accession 14 , about $6.67 \%$ of the seeds in the third crop were completely empty (data not shown).

Based on the internal and external morphological characteristics of seeds, yield and oil quality, there is a narrow genetic base among the studied accessions, despite the existence of contrasting individuals. Reis et al. (2015) also reported low variation for oil content in jatropha seeds. In the present case, the low variability can be explained by having prioritized external visual aspects of the seed in the breeding program. The accessions studied here presented on average large seeds when compared to data available in the literature (Rao et al. 2008, Santoso 2011, Reis et al. 2015). It was observed that the endosperm does not increase proportionally with the increase of the seed area. Therefore, some genotypes will exhibit large seeds, however, with the internal cavity partially occupied by the endosperm. In addition to the endosperm area, the weight of the seed also does not increase proportionally with the area of the seed. In the present study, a correlation estimated was much lower than what was expected between the weight and endosperm area. Possibly, the X-ray captured image of the endosperm stops only showing high-density regions (lighter areas), as well as the image processing itself (Figure 1). Perhaps this fact was decisive in obtaining a superior correlation between oil content and area and percentage of the endosperm in the seed. Part of the weight of the seed was due to the weight of the seed bark since the correlation between weight and seed bark was relatively high.

Kaushik et al. (2007) reported that long seeds tend to reduce oil. In the present work, it was observed that seeds less rounded, but not excessively long, tend to present higher oil content. Longer seeds also tend to reduce the concentration of monounsaturated fatty acids and increase that of polyunsaturated fatty acids in the oil, that is, they point to a reduction in the quality of this oil, considering the requirements for biodiesel synthesis, which is the main application of jatropha oil. According to Kumari et al. (2013) higher concentrations of monounsaturated fatty acids in jatropha oil result in a more stable oil after the refining process used in the preparation of biodiesel. Moser (2009) argues that relatively polyunsaturated oils are more subject to self-oxidation.

Another fact very relevant to the genetic improvement of $J$. curcas was the confirmation that the seed morphology, as well as the oil content and its composition in fatty acids, varied for the same accession during the harvest period. The selection of accessions that add stability to the endosperm and seed area during the harvest period, together with a good yield and oil quality, should now be one of the priorities in the breeding programs. The high heterozygosity in most 
Brazilian accessions may have been the main cause of the reported variation. Liu et al. (2009) reported the production of proteins in the embryo and endosperm of stress-related J. curcas seeds, such as heat shock $70 \mathrm{kDa}$ and $18.5 \mathrm{kDa}$ class I heat shock. The latter responds to stress caused by high temperatures.

It is known that the genotypes selection process should involve other variables of equal importance to those worked here, such as plants with architecture that favor the production of fruits and grains, precocity in the production, uniformity of maturation of the fruits in the cluster and increase of the seeds/grains number. However, when it is desired to achieve higher yield and oil quality in the seed, it is recommended the selection of accessions that present large, not too long and less rounded seeds, containing internal cavity filled by the endosperm, and which are stable to these variables during the harvest season. High-quality phenotyping in this case can be a powerful tool for achieving better results, especially when endosperm stability monitoring is involved.

\section{ACKNOWLEDGMENTS}

D.R. Muniz and L.A.S. Dias are supported by CNPq and FAPEMIG. The other authors thank FAPERJ for their financial support.

\section{REFERENCES}

Achten WMJ, Nielsen LR, Aerts R, Lengkeek AG, Kjaer ED, Trabucco A, Hansen JK, Maes WH, Graudal L, Akinnifesi FK and Muys B (2010) Towards domestication of Jatropha curcas. Biofuels 1: 91-107.

Akbar E, Yaakob Z, Kamarudin SK, Ismail M and Salimon J (2009) Characteristic and composition of Jatropha curcas oil seed from Malaysia and its potential as biodiesel feedstock feedstock. European Journal of Scientific Research 29: 396-403.

AOCS -Association of Official Analytical Chemists (2010) Official Methods of Analysis. $18^{\text {th }}$ edn, AOCS, Washington DC, Revision. 3.

Dahmer N, Wittman MTS and Dias LAS (2009) Chromosome numbers of Jatropha curcas L.: an important agrofuel plant. Crop Breeding and Applied Biotechnology 9: 386-389.

Dias LAS (1998) Análises multidimensionais. In Alfenas AC (ed) Eletroforese de isoenzimas e proteínas afins: fundamentos e aplicações em plantas e microrganismos. Editora UFV, Viçosa, p. 405-475.

Dias LAS, Missio RF and Dias DCFS (2012) Review Antiquity, botany, origin and domestication of Jatropha curcas (Euphorbiaceae), a plant species with potential for biodiesel production. Genetics and Molecular Research 11: 2719-2728.

Fairless D (2007) Biofuel: The little shrub that could - maybe. Nature 449: 652-655.

Ferrari RA, Casarini MB, Marques DA and Siqueira WJ (2009) Avaliação da composição química e de constituinte tóxico em acessos de pinhãomanso de diferentes origens. Brazilian Journal of Food Technology 12: 309-314.

Freitas RG, Dias LAS, Cardoso PMR, Evaristo AB, Silva MF and Araújo NM (2016) Diversityandgeneticparameterestimates for yieldand its components in Jatropha curcas L.. Genetics and Molecular Research 15: $1-10$.

Hartman L and Lago RC (1973) Rapid preparation of fatty acid methyl esters from lipids. Laboratory Practice 22: 475-476.
Jolliffe IT (1972) Discarding variables in a principal component analysis. I. Artificial data. Applied Statistics 21: 160-173.

Kaushik N, Kumar K, Kumar S, Kaushik N and Roy S (2007) Genetic variability and divergence studies in seed traits and oil content of Jatropha (Jatropha curcas L.) accessions. Biomass and Bioenergy 31: 497-502.

Kelley LA, Gardner SP and Sutcliffe MJ (1996) An automated approach for clustering an ensemble of NMR-derived protein structures into conformationally related subfamilies. Protein Engineering 9: 10631065.

Kumari R, Mallavarapu GR, Jain VK and Kumar S (2013) Corresponding properties of fatty oils of Cleome viscosa and Jatropha curcas as resources of biodiesel. Agricultural Research 2: 393-399.

Liu H, Liu YJ, Yang MF and Shen SH (2009) A comparative analysis of embryo and endosperm proteome from seeds of Jatropha curcas. Journal of Integrative Plant Biology 51: 850-857.

Maina P (2014) Investigation of fuel properties and engine analysis of Jatropha biodiesel of Kenyan origin. Journal of Energy in Southern Africa 25: 107-116.

Makkar HPS, Becker K and Schmook B (1998) Edible provenances of Jatropha curcas from Quintana Roo state of Mexico and effects of roasting on antinutrient and toxic factor in seeds. Plant Foods for Human Nutrition 52: 31-36.

Moser BR (2009) Comparative oxidative stability of fatty acid alkyl esters by accelerated methods. Journal of the American Oil Chemists' Society 86: 699-706.

R Development Core Team (2014) R: A language and environment for statistical computing. Version 3.1.2. R Foundation for Statistical Computing. Vienna.

Rao GR, Korwar GR, Shanker AK and Ramakrishna YS (2008) Genetic associations, variability and diversity in seed characters, growth, reproductive phenology and yield in Jatropha curcas (L.) accessions. Trees: Structure and Function 22: 697-709. 


\section{MS Pinto et al.}

Rasband W (2002) ImageJ 1.32v. National Institutes of Health, USA.

Reis MVM, Damasceno Junior, PC, Campos TO, Diegues IP and Freitas SC (2015) Variabilidade genética e associação entre caracteres em germoplasma de pinhão-manso (Jatropha curcas, L.), Revista Ciência Agronômica 46:412-420.

Rocha RB, Ramalho AR, Teixeira AL, Laviola BG, Silva FCG and Militão JSLT (2012) Eficiência da seleção para incremento do teor de óleo do pinhão-manso. Pesquisa Agropecuária Brasileira 47: 44-50.
Santoso BB (2011) Variation in oil contents, and seed and seedling characteristics of Jatropha curcas of West Nusa Tenggara selected genotypes and their first improved population. Nusantara Bioscience 3: $130-135$.

Spinelli VM, Rocha RB, Ramalho AR, Marcolan AL, Vieira Júnior JR, Fernandes CF, Militão JSLT and Dias LAS (2010) Componentes primários e secundários do rendimento de óleo de pinhão-manso. Revista Ciência Rural 40: 1752-1758. 